\title{
EFEKTIVITAS PERENDAMAN LARUTAN EKSTRAK DAUN BABADOTAN (Ageratum conyzoides $L$ ) DENGAN KOSENTRASI BERBEDA PADA KUALITAS TELUR AYAM RAS DALAM SUHU RUANGAN
}

\author{
Indra Rahmawati ${ }^{1}$, Junianto Wika Adi Pratama ${ }^{1}$, Mohammad Safrizal AlamHudi ${ }^{1}$, \\ Bagus Uda Palgunadi ${ }^{*}$ \\ ${ }^{1}$ Fakultas Kedokteran Hewan, Universitas Wijaya Kusuma Surabaya. \\ *Email: udapalgunadi@yahoo.com.
}

\begin{abstract}
In order to investigate the effect of immersion babadotan leaf extract solution (Ageratum conyzoides $L$ ) with various centration of the quality of chicken eggs in room temperature. Reviewed from the yolk index and haugh unit. The sample are 1 day chicken eggs race with an average weight of 50-60 grams, which is taken from PT. Mulya Broiler Farm, Binangun village, Binangun subdistrict, Blitar regency. It used as much as 100 eggs, with immersion treatment using Babadotan leaf extract solution for 1 minute with the centralization of the solution 30\%, 40\%, 50\% and 60\%, and stored in room temperature, than calculated the value of yolk index and haugh unit. Results of the study showed that immersion by using Babadotan leaf extract solution had no noticeable effect $(P>0.05)$ against the Haugh and very noticeable effect $(P<0.05)$ on the value of yolk Index. Quality of chicken eggs are given the immersion babadotan leaf extract solution is better than without immersion.
\end{abstract}

Keywords: Chicken eggs, babadotan leaf extract, room temperature, haugh unit.

\section{PENDAHULUAN}

Produk bahan pangan asal hewan dari segi sektor perunggasan, khususnya produk telur ayam ras di Indonesia, menunjukkan peningkatan angka cukup baik setiap tahunnya, berdasarkan data angka yang di terbitkan oleh Badan Pusat Statistik (BPS), menyebutkan bahwa rata-rata pada tahun 2013 berjumlah 1.224 .402 ton, pada tahun 2014 berjumlah 1.244.311.00 ton, pada tahun 2015 berjumlah 1.372 .829 .00 ton, pada tahun 2016 berjumlah 1.485 .687 .93 ton dan pada tahun 2017 berjumlah 1.527.134.87 ton. Sedangkan konsumsi telur ayam ras rata-rata di Indonesia secara per kapita pada tahun 2013 berjumlah $8.45 \mathrm{Kg}$, pada tahun 2014 berjumlah $8.55 \mathrm{Kg}$, pada tahun 2015 berjumlah $97 \mathrm{Kg}$, pada tahun 2016 berjumlah $8.55 \mathrm{Kg}$, pada tahun 2017 berjumlah 105.94 Kg (Badan Pusat Statistik, 2018).
Pernyataan Badan Pusat Statistik menyatakan bahwa angka data produksi telur ayam ras setiap tahunnya memiliki surplus atau sisa dari jumlah produksinya. Hal tersebut mengakibatkan penumpukan pada sejumlah sisa telur ayam ras yang belum dikonsumsi. Oleh sebab itu, maka perlu dilakukan perlakuan / tindakan pengawetan yang baik, sehingga telur ayam ras memiliki daya simpan lebih lama dari normalnya dan masih layak dikonsumsi.

Penurunan kualiatas ayam ras memiliki berbagai faktor penyebab salah satu penyebabnya yaitu kerusakan telur secara fisik. Selain itu menurut Muchtadi, dkk (2010) menjelaskan kerusakan telur disebabkan oleh berbagai penguapan dari dalam telur, penguapan tersebut meliputi air, karbodioksida, ammonia, nitrogen, dan hydrogen sulfida. 
Perubahan kualitas telur ayam ras menurut Cornelia, dkk (2014) menjelaskan bahwa penurunan kualiatas telur ayam ras mengalami penurunan dan perubahan pada hari ke 10-14, jika telur tersebut disimpan pada suhu ruangan yang memiliki suhu yang lembab dan tidak stabil. Perubahan tersebutditandaidengan perubahan berat telur, perubahan komposisi kandungan kimia telur dan pastinya pengenceran isi dari telur tersebut.

\section{MATERI DAN METODE.}

\section{Alat dan bahan.}

Adapun alat penelitian yang akan digunakan yaitu : Egg tray (rak tempat telur), jangka sorong (kaliper), kalkulator, meja kaca datar, glove (sarung tangan), kapas, spidol, kertas label, baskom dan tisu.Bahan yang akan digunakan dalam penelitian yaitu: Telur ayam ras, aquades dan cairan ekstrak daun babadotan solid.

\section{Metode}

Penelitian ini menggunakan telur ayam ras berumur 1 hari dengan berat rata-rata 5060 gram, kemudian direndam dengan larutan ekstrak babandotan dengan konsentrasi $30 \%$, $40 \%, 50 \%$ dan $60 \%$ selama 1 menit, dan disimpan pada suhu ruangan. Ditinjau menggunakan IKT dan HU selama 4 minggu.

\section{HASIL}

\section{Haugh Unit (HU)}

Hasil analisis nilai Haugh Unit (HU) pada telur ayam ras yang dilakukan selama 4 minggu dengan metode perendaman larutan ekstrak daun babadotan, dan diberikan perlakuan $\mathrm{P} 0=$ Kontrol, $\mathrm{P} 1=30 \%$ larutan ekstrak daun babadotan, $\mathrm{P} 2=40 \%$ larutan ekstrak daun babadotan, $\mathrm{P} 3=50 \%$ larutan ekstrak daun babadotan, dan P4 $=60 \%$.
Tabel 1. Rata-Rata Nilai Haugh Unit (HU)

\begin{tabular}{ll}
\multicolumn{1}{c}{ Perlakuan } & \multicolumn{1}{c}{ Rata-rata \pm SD } \\
\hline \multirow{2}{*}{ P0 (Kontrol) } & $18.17840 \pm$ \\
& $12.389848^{\mathrm{a}}$ \\
\hline P1 (laruran ekstrak & $20.76160 \pm$ \\
babadotan 30 \%) & $15.591095^{\mathrm{a}}$ \\
\hline P2 (larutan ekstrak & $31.27060 \pm$ \\
babadotan 40 \%) & $18.571866^{\mathrm{a}}$ \\
\hline P3 (larutan ekstrak & $33.03420 \pm$ \\
babadotan 50\%) & $6.944835^{\mathrm{a}}$ \\
\hline P4 (larutan ekstrak & $30.84720 \pm$ \\
babadotan 60\%) & $8.121207^{\mathrm{a}}$ \\
\hline
\end{tabular}

Keterangan :Sumber data primer yang diolah, nilai rata-rata pada kolom yang tidak sama diikuti superskip yang tidak berbeda, mununjukkan tidak adanya perbedaan yang nyata $(\mathrm{P}>0,05)$.

Rata-rata nilai Haugh Unit (HU) tertinggi terdapat pada telur ayam ras yang diberi perlakuan perendaman ekstrak daun babadotan (P3) yaitu $33.03420 \pm 6.944835$ a dan rata-rata nilai Haugh Unit (HU) terendah pada telur ayam ras yang tanpa diberikan perlakuan (P0) yaitu $18.17840 \pm 12.389848 \mathrm{a}$.

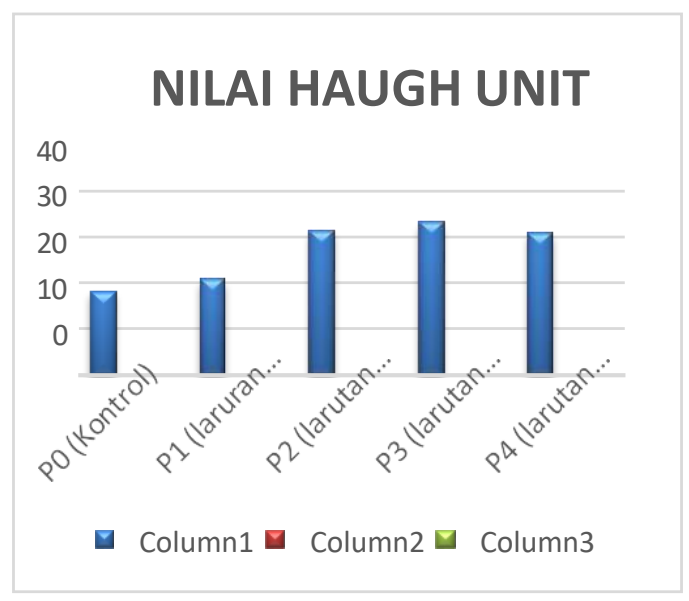

Gambar 1.Grafik rata-rata nilai Haugh Unit (HU) telur ayam ras. 
Tabel 2.Indeks KuningTelur (IKT)

\begin{tabular}{lc}
\hline \multicolumn{1}{c}{ Perlakuan } & Rata-rata \pm SD \\
\cline { 1 - 1 } P0 (Kontrol) & $0.07180 \pm .047960^{\mathrm{a}}$ \\
\cline { 1 - 1 } $\begin{array}{l}\text { P1 (laruran ekstrak } \\
\text { babadotan 30\%) }\end{array}$ & $0.14160 \pm .086468^{\mathrm{b}}$ \\
$\begin{array}{l}\text { P2 (larutan ekstrak } \\
\text { babadotan 40 \%) }\end{array}$ & $0.18160 \pm .025235^{\mathrm{b}}$ \\
$\begin{array}{l}\text { P3 (larutan ekstrak } \\
\text { babadotan 50\%) }\end{array}$ & $0.19360 \pm .008620^{\mathrm{b}}$ \\
$\begin{array}{l}\text { P4 (larutan ekstrak } \\
\text { babadotan 60\%) }\end{array}$ & $0.20560 \pm .040166^{\mathrm{b}}$ \\
\hline
\end{tabular}

Keterangan: Sumber data primer yang diolah, nilai rata-rata pada kolom sama diikuti superskip yang berbeda, menunjukkan adanya perbedaan yang sangat nyata $(\mathrm{P}<0,05)$.

Hasil analisis nilai Indeks Kuning Telur (IKT) pada telur ayam ras yang dilakukan selama 4 minggu dengan metode perendaman larutan ekstrak daun babadotan, dan diberikan perlakuan $\mathrm{P} 0=$ Kontrol, $\mathrm{P} 1=30 \%$ larutan ekstrak daun babadotan, P2 $=40 \%$ larutan ekstrak daun babadotan, P3 $=50 \%$ larutan ekstrak daun babadotan, dan $\mathrm{P} 4=60 \%$.

Nilai Indeks KuningTelur (IKT) pada telur ayam ras dengan perlakuan perendaman larutan ekstrak daun babadotan.

Rata-rata nilai Indeks KuningTelur (IKT) tertinggi terdapat pada telurayamras yang diberi perlakuan perendaman ekstrak daun babadotan $(\mathrm{P} 4)$ yaitu $0.20560 \pm .040166 \mathrm{~b}$ dan rata-rata nilai Indeks Kuning Telur (IKT) terendah pada telur ayam ras yang tanpa diberikan perlakuan (P0) yaitu $0.07180 \pm$ .047960a. Hasil ini didukung juga dengan uji ANOVA dengan taraf signifikan lebih dari $0,05(\mathrm{P}<0,05)$ maka $\mathrm{H} 1$ tidak dapat diterima. Sehingga dapat dikatakan bahwa terdapat pengaruh nyata perendaman larutan ekstrak babadotan terhadap Indeks KuningTelur (IKT) pada telur ayam ras.

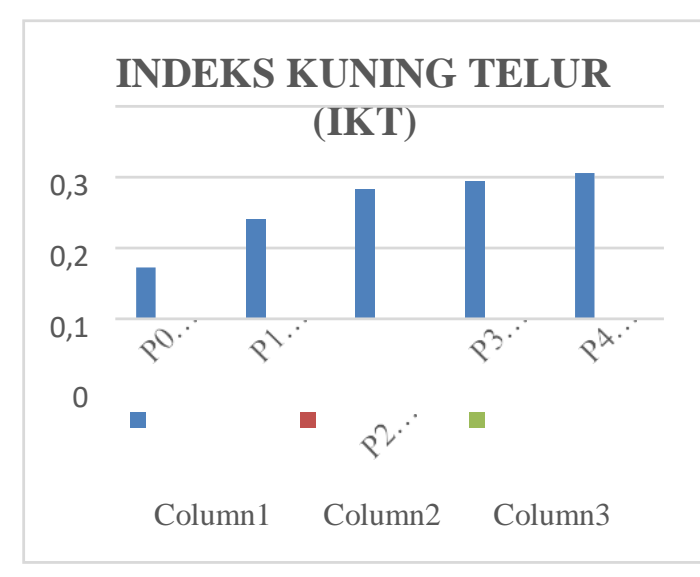

Gambar 2.Grafik rata-rata nilai Indeks Kuning Telur (IKT) telur ayam ras.

\section{PEMBAHASAN}

\section{Haugh Unit}

Berdasarkan analisis ragam yang telah dilakukan, menunjuk- kan bahwa penggunaan metode perendaman larutan daun babadotan pada telur ayam ras tidak berpengaruh nyata $(\mathrm{P}>0,05)$ terhadap nilai haugh unit $(\mathrm{HU})$, akan tetapi rata-rata dari analisis ragam tersebut menunjukkan bahwasannya semakin tinggi kosentrasi larutan ekstrak daun babadotan maka semakin tinggi pula nilai haugh unit yang dihasilkan meskipun terbilang tipis perbandingannya.

Menurut Sulistina, dkk (2017) menyatakan bahwa, kemungkinan yang terjadi bahwa banyaknya karbondioksida dan gas lainnya keluar dari dalam telur ayam ras, yang diduga karena tannin tidak dapat menutupi pori-pori telur dengan sempurna.

Berdasarkan pernyataan dari Stadelman dan Cotteril (1997) dalam Novita A (2014) menyatakan bahwa, tingginya nilai haugh unit (HU) dipengaruhi oleh kandungan ovomucin yang terdapat pada kandungan putih telur, apabila kandungan ovomucin semakin tinggi maka nilai HU yang diperoleh juga semakin tinggi dan juga sebaliknya. Lama penyimpanan berpengaruh sangat nyata 
terhadap nilai HU pada telur ayam ras, ratarata dari keseluruhan nilai $\mathrm{HU}$ yang didapat menunjukkan bahwa, semakin lama penyimpanan telur ayam ras maka semakin rendah pula nilai HU yang dihasilkan.

\section{Indeks KuningTelur (IKT)}

Hasil penilitian menunjukkan bahwa perendaman dengan menggunakan larutan ekstrak daun babadotan berpengaruh sangat nyata $(\mathrm{P}<0,05)$ terhadap nilai Indeks Kuning Telur (IKT). Rata-rata penambahan kosentrasi larutan ekstrak daun babadotan menunjukkan bahwa semakin tinggi kosentrasi maka semakin tinggi pula nilai dari indeks kuning telurnya (IKT) yang dihasilkan.

Hal ini dikarenakan senyawa antibakterial yang terdapat pada larutan esktrak daun babadotan mampu melindungi kuning telur terhadap aktifitas bakterial yang terdapat pada permukaan kulit telur. Indeks kuning telur diperoleh dari tinggi dan luas kuning telur, penyebab kuning telur melemah disebabkan oleh umur telur yang mempengaruhi kekuatan dan elastisitas membrane vetelin telur, melemahnya membrane veteline dapat diamati dengan cara pengukuran nilai indeks kuning telur (IKT) (Novita A, 2014).

Berdasarkan pernyataan dari Shenstone (1968) dalam Novia A (2014) menjelaskan bahwa umur telur semakin bertambah maka nilai dari IKT semakin menurun yang disebabkan karena adanya perpindahan air. Perpindahan air tersebut disebabkan oleh adanya tekanan osmotic dari kuning telur yang besar terhadap putih telur, sehingga cairan yang ada pada putih telur masuk ke dalam kuning telur. Menurut Lestari (2011) menyatakan bahwa terjadinya viskositas kuning telur menurun diakibatkan karena perpindahan air secara terus menerus, kemudian kuning telur menjadi lebih pipih dan mudah pecah.

\section{KESIMPULAN}

Berdasarkan hasil anaslis penelitian dapat disimpulkan bahwa tidak adanya pengaruh perendaman larutan ekstrak daun babadotan terhadap telur ayam ras pada nilai haugh unit (HU). Serta adanya pengaruh perendaman larutan ekstrak daun babadotan terhadap telur ayam ras pada nilai indeks kuning telur (IKT).

\section{REFERENSI}

Badan Pusat Statistik. 2018. "Produksi dan Konsumsi Telur Ayam ras Indonesia".

Muchtadi, T,R.,Putri.S.W. F dan Sugiyono. 2010. "Ilmu Pengetahuan Bahan Pangan. Penerbit Alfabeta”. Bandung.

Cornelia.A, I. K. Suada dan M.D. Rudyanto. 2014. "Perbedaan Daya Simpan Telur Ayam Ras yang Dicelupkan dan Tanpa Dicelupkan Larutan Kulit Manggis". Indonesia Medicus Veterinus3 (2) : 112 - 119 ISSN : 2301-7848.

Sulistina, L., Imanudin, O., Falahudin,A. 2017. "Pengaruh Perendaman Ekstrak Teh Hijau (Camellia sinensis) Terhadap Kualitas Interior Telur Ayam Ras". Program Studi Peternakan. Fakultas Peternakan. Universitas Majalengka.

Novita, A. 2014. "Potensi Daun Bandotan (Ageratum conyzoides L) Sebagai Bahan Curing Alamiah Telur Ayam Ras". Laboratorium Kesehatan Masyarakat Veteriner. Fakultas Kedokteran Hewan. Universitas Syiah Kuala, Banda Aceh.

Lestrai, L., Malaka, R., Grantjang, S. 2011. "Pengawetan Telur Dengan Perendaman Ekstrak Daun Mlinjo (Gnetum Gnemon Linn)”. Fakultas Peternakan, PascaSarjana, Universitas Hasanuddin. 